\title{
To estimate the prevalence and type of ocular trauma
}

\author{
Mahendra Kumar Meena ${ }^{1}$, Vijay Gupta ${ }^{2}, *$ \\ ${ }^{1}$ Resident Doctor, ${ }^{2}$ Professor, Dept. of Ophthalmology, RNT Medical College, Udaipur, Rajasthan, India \\ *Corresponding Author: \\ Email: vijaygupta19682@yahoo.com
}

\begin{abstract}
Objectives: To estimate the prevalence and type of ocular trauma patients admitted and referred to department of ophthalmology, RNT Medical College, and associated group of hospital Udaipur, from May 2016 to Oct. 2017.

Materials and Methods: A prospective study conducted over a period of 1.5 year in which all patients of Ocular injury admitted or referred in department of ophthalmology, RNT Medical College and associated groups of hospital, Udaipur. After enrollment a thorough clinical examination with torch light and slitlamp will be carried out. Slit lamp examination includes documentation of size of tear, its location, involvement of visual axis, iris prolapse, cataract formation and IOFB.

Results: Out of 30 patients 4 are females and 26 are males. Male female ratio was 6.50:1. Mean age of patients injured was 27.1 . Percentage of injured patient's admission was high during winter season (40\%). Most of the patients $(60 \%)$ come in hospital with in 24 hours of injury. Work place was the most common place $(56.66 \%)$ of injury followed by home (26.66\%). Wooden stick were most common object causing injuries in both male $(38.46 \%)$ and female $(50 \%)$. The incidence of open globe injuries $(86.66 \%)$ was more than closed globe injuries $(13.33 \%)$.

Conclusion: Males are more prone to injury than females in all age groups. Rural environment is more exposed to ocular injury. Work place was the most common place of injury in male and female. Open globe injury is main culprit for hospitalization in ocular trauma.
\end{abstract}

Keywords: Corneal tear, Ocular trauma.

\section{Introduction}

Eye is the organ for sense of vision which is one of the most valued and powerful senses nature has bestowed us. Eyes represent only $0.1 \%$ of the total body surface and only $0.27 \%$ of the anterior body surface but their significance to individuals is disproportionally higher. ${ }^{1}$ Any harm to the eyeball may affect development, independency, quality of life and safety of an individual, so nature has provided various protective mechanisms. ${ }^{2}$ Eyelids close reflexively at the first sight of sound of danger and eyelashes prevent small particle to reach the eyeball. Cornea is so sensitive that the smallest foreign body is felt instantly and painfully so that the signal for defence goes out. Despite all these protective mechanisms, eyes remain quite vulnerable to trauma.

Trauma has long been considered a result of random, unrelated, and unpreventable factor rather than a disease and received far less attention. ${ }^{1}$ Ocular trauma once described as the neglected disorder ${ }^{3}$ has recently been highlighted as a major cause of visual morbidity and considered as important public health hazard with enormous economic and social consequences. ${ }^{4}$ WHO program for the prevention of blindness suggests that around 55 million eye injuries, restricting activities for one day, occur each year. 750,000 cases require hospitalization each year including 200,000 open globe injuries. There are approximately 1.6 million people blind in addition to 2.3 million people with bilateral low vision from the cause. Unilateral blindness or low vision affects around 19 million people. ${ }^{5}$

The ocular injury may involve lids, lacrimal apparatus, bony orbit, the adjacent structure, the eyeball and the visual pathway. Incidence for hospitalisation after ocular injuries varies among different countries for instance 6.8 per 1000 in united states, ${ }^{6} 20.53 \%$ in India ${ }^{7}$ and $12.9 \%$ in Pakistan. ${ }^{8}$

The incidence of ocular injuries varies from country to country depending on degree of industrialization of area and whether the incidence of superficial foreign bodies and minor injuries is included in the estimate or not. Although ocular trauma affects all age groups, the distribution for occurrence of serious ocular trauma in bimodal with maximum incidence in young adults and another peak in elderly. ${ }^{2}$

Table 1: Standarized terminology of ocular injury by beets ${ }^{3}$

\begin{tabular}{|c|c|c|}
\hline Term & Definition & Remarks \\
\hline Eyewall & Sclera and cornea & $\begin{array}{l}\text { Though the eyewall has three layers posterior to the limbus, } \\
\text { for clinical and practical purposes violation of only the } \\
\text { most external structure is taken into consideration }\end{array}$ \\
\hline Closed globe injury & $\begin{array}{l}\text { No full thickness wound of } \\
\text { eyewall }\end{array}$ & The cornea and sclera are not breached through and through \\
\hline Open globe injury & $\begin{array}{l}\text { Full thickness wound of } \\
\text { eyewall }\end{array}$ & $\begin{array}{l}\text { The cornea or sclera is breached through and through by } \\
\text { injury }\end{array}$ \\
\hline
\end{tabular}




\begin{tabular}{|l|l|l|}
\hline Contusion & No wound of eyewall & $\begin{array}{l}\text { The injury is either due to direct energy delivery by the } \\
\text { object (e.g., choroidal rupture)or to the changesin the shape } \\
\text { of the globe(e.g. angle recession) }\end{array}$ \\
\hline Lamellar laceration & $\begin{array}{l}\text { Partial -thickness wound of } \\
\text { eyewall }\end{array}$ & The wound of eye wall is not through but into \\
\hline Rupture & $\begin{array}{l}\text { Full- thickness wound of } \\
\text { the eyewall, caused by a } \\
\text { blunt object. }\end{array}$ & $\begin{array}{l}\text { Since the eye is filled with incompressible liquid, the } \\
\text { impact results in momentary increase of the IOP. The } \\
\text { eyewall yields at its weakest point (at the impact site or } \\
\text { elsewhere; example: an old cataract wound dehisces even } \\
\text { though the impact occurred elsewhere); the actual wound is } \\
\text { produced by an inside- out mechanism }\end{array}$ \\
\hline Laceration & $\begin{array}{l}\text { Full- thickness wound of } \\
\text { the eyewall, caused by a } \\
\text { sharp object. }\end{array}$ & $\begin{array}{l}\text { The wound occurs at the impact site by an outside- in } \\
\text { mechanism }\end{array}$ \\
\hline Penetrating injury & $\begin{array}{l}\text { Entrance wound. } \\
\text { Intraocular foreign } \\
\text { body }\end{array}$ & $\begin{array}{l}\text { One or more foreign objects } \\
\text { are present }\end{array}$ \\
\hline $\begin{array}{l}\text { Superficial foreign } \\
\text { body }\end{array}$ & $\begin{array}{l}\text { Closed globe injury } \\
\text { resulting from a projectile } \\
\text { but not full thickness } \\
\text { eyewall defect }\end{array}$ & $\begin{array}{l}\text { Technically a penetrating injury, but grouped separatley } \\
\text { because of different clinical implications }\end{array}$ \\
\hline
\end{tabular}

\section{Materials and Methods}

A prospective study conducted over a period of 1.5 year in which all patients of Ocular injury admitted or referred in department of ophthalmology, RNT Medical College and associated groups of hospital, Udaipur during the study period will be included.

\section{Inclusion Criteria:}

1. Any patient of ocular injury irrespective of age and sex admitted in department of ophthalmology \& surgical intervention done in eye OT.

2. Patients of ocular injury referred to with or without primary treatment which are admitted in department of ophthalmology \& surgery carried out in eye OT.

\section{Exclusion Criteria:}

1. Patients of ocular injury who had been operated elsewhere, attending our department for follow up only.

2. Ocular trauma patients were taking treatment on OPD basis.

3. Patients of ocular injury having associated with severe systemic injury.

4. Patient with posterior segment involvement.

In this study detailed history including demographic data, mode of injury, about primary management, time gap between injury and presentation to the hospital will be recorded.

After enrollment a thorough clinical examination with torch light and slit lamp will be carried out. Slit lamp examination includes documentation of size of tear, its location, involvement of visual axis, iris prolapse, cataract formation and IOFB.

\section{Results}

From 1 May 2016 to 31 October 2017 total 1874 patients admitted in Department of ophthalmology, R.N.T. Medical College, Udaipur out of which 36 patients admitted for ocular trauma in which 6 patient was not attended follow up so they are excluded from study and study were limited to 30 patients.

Out of 30 patients 4 are females and 26 are males. Male female ratio was 6.50:1. Mean age of patients injured was 27.1 years; it was somewhat younger in males (26.5 yrs) and elder in females (31 yrs).

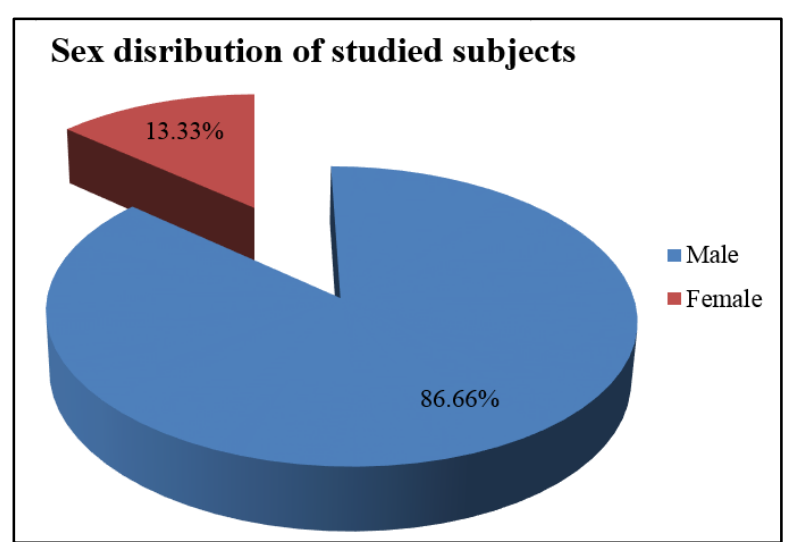

Fig. 1

Table 2: Distribution of patients according to month of admission

\begin{tabular}{|l|c|c|}
\hline \multicolumn{1}{|c|}{ Month } & $\begin{array}{c}\text { No. of } \\
\text { patients }\end{array}$ & Percentage \\
\hline May-July (2016) & 4 & $13.33 \%$ \\
\hline August-October (2016) & 1 & $3.33 \%$ \\
\hline November (2016)- & 12 & $40 \%$ \\
\hline
\end{tabular}




\begin{tabular}{|l|c|c|}
\hline January (2017) & & \\
\hline February-April (2017) & 7 & $23.33 \%$ \\
\hline May-July (2017) & 2 & $6.66 \%$ \\
\hline August-October (2017) & 4 & $13.33 \%$ \\
\hline Total & 30 & $100 \%$ \\
\hline
\end{tabular}

Percentage of injured patients admission was high during winter season (40\%). Most of the patients $(60 \%)$ come in hospital with in 24 hours of injury.

Work place was the most common place $(56.66 \%)$ of injury followed by home $(26.66 \%)$

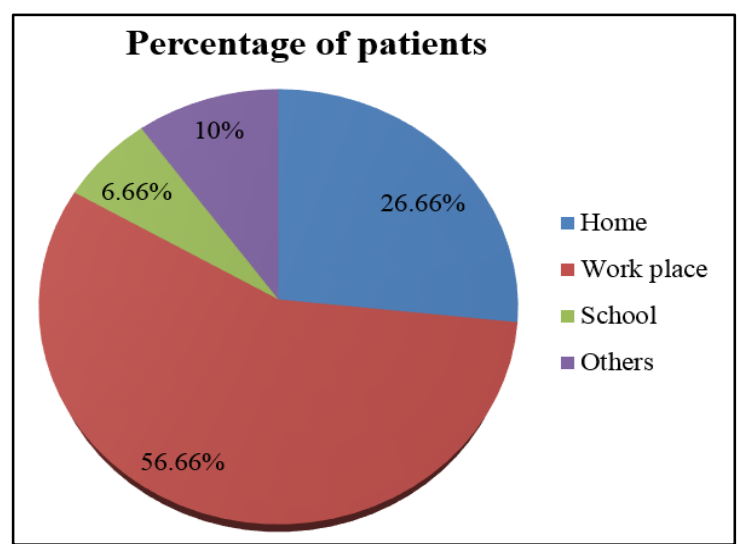

Fig. 2

Table 3: Distribution of objects of injury in males and females in different age groups

\begin{tabular}{|l|c|c|c|c|c|c|c|c|c|c|c|c|c|}
\hline \multirow{2}{*}{ Objects causing } & \multicolumn{2}{|c|}{ 0-10 } & \multicolumn{2}{|c|}{$\mathbf{1 1 - 2 0}$} & \multicolumn{2}{|c|}{$\mathbf{2 1 - 3 0}$} & \multicolumn{2}{|c|}{$\mathbf{3 1 - 4 0}$} & \multicolumn{2}{|c|}{$\mathbf{4 1 - 5 0}$} & \multicolumn{2}{|c|}{$\mathbf{5 1 - 6 0}$} & \multirow{2}{*}{ Total } \\
\cline { 2 - 14 } & $\mathrm{M}$ & $\mathrm{F}$ & $\mathrm{M}$ & $\mathrm{F}$ & $\mathrm{M}$ & $\mathrm{F}$ & $\mathrm{M}$ & $\mathrm{F}$ & $\mathrm{M}$ & $\mathrm{F}$ & $\mathrm{M}$ & $\mathrm{F}$ & \\
\hline Wooden stick/piece & 4 & - & - & - & 2 & 2 & 2 & - & 2 & - & - & - & 12 \\
\hline Stone & - & - & - & - & 3 & - & 2 & - & 1 & - & - & - & 6 \\
\hline Metal piece & - & - & 2 & - & 1 & - & - & - & 1 & - & - & - & 4 \\
\hline Glass piece & - & - & - & - & 1 & - & 1 & - & - & - & - & - & 2 \\
\hline Pencil & - & - & 3 & 1 & - & - & - & - & - & - & - & - & 4 \\
\hline Blast injury & - & - & 1 & - & - & - & - & - & - & - & - & - & 1 \\
\hline Animal & - & - & - & - & - & - & - & - & - & - & - & 1 & 1 \\
\hline
\end{tabular}

$40 \%$ cases (12 out of 30 ) are presented with trauma by wooden stick followed by stone particle injury $(20 \%)$.

Wooden stick were most common object causing injuries in both male $(38.46 \%)$ and female $(50 \%)$. The incidence of open globe injuries $(86.66 \%)$ was more than closed globe injuries (13.33\%). Most common clinical findings at the time of presentation was corneal tear $(50 \%)$ followed by traumatic cataract $(30 \%)$.

The common surgical procedures were corneal suturing $(60 \%)$ and scleral suturing $(13.33 \%)$.

$60 \%$ patients had improvement in visual acuity after 6 weeks, $33.33 \%$ patients had no change in visual acuity.

Table 4: Comparison of visual acuity preoperative and postoperative (after 6 week)

\begin{tabular}{|l|c|c|}
\hline Visual acuity & No. of patients preoperative & No. of patients postoperative \\
\hline PL absent & 3 & 3 \\
\hline PL to HM present & 16 & 5 \\
\hline FC $-1 \mathrm{ft}$ to $<6 / 60$ & 6 & 8 \\
\hline $6 / 60$ to $<6 / 24$ & 2 & 6 \\
\hline $6 / 24$ to $<6 / 18$ & 1 & 1 \\
\hline $6 / 18$ to $6 / 6$ & 1 & 6 \\
\hline Cannot be assessed & 1 & 1 \\
\hline
\end{tabular}

Most of patients (60\%) usually had shown improvement in visual acuity after primary repair at 6 weeks.

\section{Discussion}

This is a hospital based prospective case series study of ocular injuries. Out of 1874 patients, 30 cases (1.60\% of total admission) of ocular injuries got admited for management of ocular trauma. Malik S et al (December 2007) reported ocular trauma patients an incidence of $2.7 \%$ of total ophthalmic admission.
Male patients were predominated in this study group with $86.66 \%$ and female were $13.33 \%$ [Fig. 1]. It is similar to as reported by Parul Desai et al (1996) ${ }^{9}$ [sex ratio 5.4: 1] but higher than 2: 1 as observed by Nirmalan et al (2004). ${ }^{10}$

In this study mean age of presentation was 27.1 years; it was somewhat younger in male (26.5 years) and elder in female (31 years). Percentage of admission have bimodal seasonal distribution first peak in February-April (23.33\%) and second peak in winters $(40 \%)$ at time of agriculture work similar results also shown by Rajendra P. Maurya et al(2013). ${ }^{11}$ (Table 2) 
Most of the patients (60\%) presented early within 24 hours of injury. S R Malik et al (1968) reported that $83.1 \%$ cases attended hospital within 24 hours. ${ }^{12}$

There was no significant tendency towards right or left eye in this study both being affected equally. Tsedeke Asaminew et al (2009) also reported right and eyes were affected equally, $49.7 \%$ right and $50.0 \%$ left. $^{4}$

In this study, work place was the most common place $(56.66 \%)$ of injury followed by home $(26.66 \%)$. As per Boo Sup Oum et al (2004) study $34.9 \%$ injuries occurred at workplace, $32.2 \%$ at home and $25 \%$ at street ${ }^{13}$ (Fig. 2).

The incidence of open globe injuries $(86.66 \%$ ) was more than closed globe injuries (13.33\%). Boo Sup Oum et al (2004) reported closed globe injuries (85.8\%) were more common than open globe (14.2\%) injuries in patients presented to emergency department. ${ }^{13}$

Most common clinical findings were by cornal tear (50\%), followed by $33.33 \%$ traumatic cataract.

Most of patients (60\%) usually shown improvement in visual acuity after primary repair at 6 weeks, $33.33 \%$ patients shown no visual improvement and $3.33 \%$ patients shown deterioration in visual acuity. But it was not their BCVA, vision further improved after suture removal, traumatic Cataract removal, etc. [Table 4]

\section{Conclusion}

Males are more prone to injury than females in all age groups. Rural environment is more exposed to ocular injury. Work place was the most common place of injury in male and female. Open globe injury is main culprit for hospitalization in ocular trauma. So attention required of health care planners to improve medical and surgical facilities mainly in rural area by appointing ophthalmologist, anesthetist and by providing better surgical facilities.

\section{References}

1. Kuhn F, Mester V, Mann L, Witherspoon CD, Morris R, Maisiak R. Eye Injury Epidemiology and Prevention of Ophthalmic Injury. In: Kuhn F, Pieramici DJ, editors. Ocular Trauma Principles and Practice, $\mathrm{I}^{\text {st }}$ ed. New York: Thieme Medical Publisher; 2002. p. 14-21.

2. Glynn RJ, Seddon JM, Berlin BM. The incidence of eye injuries in New England adults. Arch Ophthalmol. 1988;106(6):785-9.

3. Kuhn F, Morris R, Witherspoon CD, Hiemann K, Jefferers J, Treister G. A standardized classification of ocular trauma terminology. Ophthalmology. 1996;103(2):240-243.

4. Parver L. Eye trauma, The Neglected Disorder. Arch Ophthalmol. 1986;104:1452-3.

5. Asaminew T, Gelaw Y, Alemseged F. A 2-Year review of ocular trauma in JIMMA University specialized hospital. Ethiop J Health Sci. 2009;19(2):67-74.

6. Negrel AD, Thylefors B. The Global impact of eye injuries. Ophthalmic Epidemiol. 1998;5(3):143-69.

7. McGwin G, Owsley C. Incidence of Emergency Department- Treated Eye Injury in the United States.
Arch Opthalmol. 2005;123(5):662-66

8. Panda A, Bhatia IM, Dayal Y. Ocular injuries incidence. Afro Asian J Ophthalmol. 1985;3:170-71.

9. Khan MD, Mohammad S, Islam ZU, Khattak MN. An 11 years review of ocular trauma in the North West Frontier Province of Pakistan. Pak J Ophthalmol. 1991;7:15-18.

10. Desai P, MacEwen CJ, Baines P, Minassian DC. Incidence of cases of ocular trauma admitted to hospital and incidence of blinding outcome. Br J Ophthalmol. 1996;80(7):592-96.

11. Nirmalan PK, Katz J, Tielsch JM, et al. Ocular trauma in a rural south Indian population: the Aravind Comprehensive Eye Survey. Ophthalmology. 2004;111(9):1778-81.

12. Rajendra P. Maurya, Kundan Sinha, Prithvi R. Sen, et al. A Clinico-Epdemiological study of ocular trauma in Indian university students. Pak J Ophthalmol. 2013;29(2)80-88.

13. Malik S, Gupta A K, Chaudhary S. A study on pattern of ocular injuries in Delhi. Indian J Ophthalmol. 1968;16(4):178-82.

14. Boo Sup Oum, Jong Soo Lee, Young Sang Han. Clinical Feature of Ocular Trauma in Emergency Department. Korea J Ophthalmol. 2004;18(1):70-78.

How to cite this article: Meena MK, Gupta V. To estimate the prevalence and type of ocular trauma. Ind J Clin Exp Ophthalmol. 2018;4(3):320-323. 